\title{
A Cambodian-Norwegian Competence Building Program in Child Mental Health: A Qualitative Focus-Group Study
}

Marit Hafting ( $\sim$ Marit.Hafting@gmail.com )

NORCE Norwegian Research Centre AS https://orcid.org/0000-0003-2334-8192

\section{Puthy Pat}

Caritas-CCAMH, Phnom Penh

\section{Gunn Aadland}

University Hospital of Stavanger

Krister Fjermestad

University of Oslo

Bhoomikumar Jegannathan

Caritas-CCAMH, Phnom Pehn

\section{Research article}

Keywords: Transcultural competence building, child and adolescent mental health and neurodevelopmental disorders, low-and middle-income countries, Cambodia

Posted Date: November 18th, 2020

DOl: https://doi.org/10.21203/rs.3.rs-106321/v1

License: (c) (1) This work is licensed under a Creative Commons Attribution 4.0 International License. Read Full License 


\section{Abstract}

\section{Background}

The prevalence of mental health and neurodevelopmental disorders in young people is high in low- and middle-income counties, such as Cambodia, as risk factors in the perinatal period, malnutrition, infections and adverse childhood experiences can be abundant due to poverty and/or conflict. Collaboration between institutions from high-income countries and institutions in resource-poor settings for professional development can improve service providers' knowledge and skills, which is key to bridging the gap between service needs and the ability to meet those needs. The aim of the present article is to describe some significant aspects of a transcultural capacity-building program in child mental health.

\section{Methods}

A Norwegian team comprised of a pediatrician, a child and adolescent psychiatrist and a child psychologist implemented a program for competence building at Centre for Child and Adolescent Mental Health (Caritas-CCAMH) in Cambodia two weeks per year over a 14-year period. Herein, we explore some aspects of this collaboration from the perspective of the Caritas-CCAMH staff with a qualitative approach using thematic analysis of the transcripts from a focus-group interview with 11 staff members at the end of the 14-year period.

\section{Results}

The multidisciplinary team at Caritas-CCAMH described a learning process characterized by collaboration in planning and implementation. Mixing theory and practice in clinical case discussions with a biopsycho-social perspective was perceived as the cornerstone of the pedagogical process. Learning by observation and supervision from the Norwegian team led to mastering skills and enhancing selfconfidence and job satisfaction. A pedagogical strategy that involved constant reflection back and forth enabled the customization of the content and method of capacity building despite the differences in socio-economic conditions and learning styles that were unfamiliar to the mental health professionals from a high-income country.

\section{Conclusions}

Building knowledge and skills within a dialogic partnership over a significant period of time contributed to learning across cultures. This model of continuity, low-investment and low-intensity capacity-building may enrich the child and adolescent mental health settings in low- and middle-income countries. Furthermore, the model appears feasible for Western professionals with an ambition to support.

\section{Background}


Acknowledging the burden of mental health problems in low- and middle-income countries (LMIC), World Health Organization (WHO) has developed the Mental Health Action Plan 2013-2020 (1) to expand services for those with mental health disorders in low-resource settings. A subdomain of specific importance is the mental health of children and adolescents (2). The fact that $50 \%$ of mental health disorders have emerged by the age of 14 years and $75 \%$ by the age of 24 years, underscores the reason that investing in the mental health of children and adolescents is a global priority (3). Though strategies for the promotion, prevention and treatment of mental health issues among children and young people are well documented $(4,5,6)$, the gap between the service needs and the availability of services remains wide due to inter alia funding constraints, misplaced priorities and a lack of human resources (7).

Strengthening the provision of mental health services to young people in LMIC can be reached through multiple tracks. Juengsiragulwit (8) refers to the following, taken from WHO-AIMS (9): policy and legislative frameworks, mental health specialist services, mental health in primary health care, human resources, public education and links with other sectors, monitoring, and research. According to the WHO Mental Health Gap Action Programme (mhGAP) (10), mental health, neurological and substance use disorders rely heavily on health personnel resources rather than on technology and equipment. Therefore, enhancing human resources, including adequate and appropriate training, is necessary for scaling up health interventions for young people with mental health problems. The mhGAP goal is "to get the right workers with the right skills in the right place doing the right things" $(10, \mathrm{p} 18)$.

There are mental health projects worldwide with documented evidence concerning the enhancement of human resources and capacity building in LMICs, targeting health professions in specialist health care (11) and primary health care $(12,13,14)$. "Scaling up," "task-shifting" and "dissemination" are central concepts, meaning to provide mental health care through transference of competence from specialisttrained personnel to primary health-care workers (15). Some of these projects are partnerships between mental health professions from developed and developing countries $(8,16,17)$.

The current article explores the experiences from a capacity building program over 14 years at Centre for Child and Adolescent Mental Health in Cambodia (Caritas-CCAMH), performed by mental health and paediatric personnel from Norway. To the best of our knowledge, there are few reports of capacity building programs seen from the local staff members' point of view. The aim of this research project is therefore to describe from the perspective of the local staff some significant aspects of a transcultural program in capacity building in child mental health in LIMIC, among other things relevant for Western clinicians with an ambition to support.

\section{The setting: The Cambodian-Norwegian capacity building program}

The Cambodian health system collapsed during the Khmer Rouge era, and the two decades of internecine war made the situation worse because trained personnel were unavailable to provide quality services (18). Cambodia is a LMIC, post-conflict country with an emerging economy in Southeast Asia. The 
estimated population is 15.6 million, and approximately $85 \%$ of the Cambodian population lives in rural communities.

\section{Caritas-CCAMH}

Being the pioneering service for children with mental health problems in Cambodia, Caritas-CCAMH, near Phnom Penh, is a public-private partnership between Ministry of Health Royal Government of Cambodia and Caritas Cambodia (19).

Since 1995, the Caritas-CCAMH team has provided clinical services for children and adolescents with mental health and neurodevelopmental disorders (MNDD). The main problem presentations among patients include developmental problems (mainly autism and intellectual delay, 60\%), neuropsychiatric problems (mainly epilepsy and tic disorders, 20-25\%), and psychological problems (mainly psychosis and anxiety disorders, 10-20\%). Currently, the staff at Caritas-CCAMH performs around 5,000 consultations per year at their main clinic and remote service centers. Additional emphasis is given to human resource development, capacity building, outreach services to remote provinces, research and documentation in accordance with Fricchione et al. (15).

The Caritas-CCAMH team is multidisciplinary. The team comprises 16 mental health workers, most of them have credentials in education, but their training in child and adolescent MNDD is short and basic. To overcome this challenge, the Caritas-CCAMH team has established collaboration with institutions in Egypt, India, Norway, Singapore, Sweden, Thailand and the United Kingdom. The Caritas-CCAMH staff can access training in some of these institutions, and professionals from these institutions visit Cambodia.

\section{The Norwegian team (NT)}

The NT, comprised of the same pediatrician and child and adolescent psychiatrist from 2005-2018, supplemented by child psychologist from 2013-2018, have had yearly two-week stays at CaritasCCAMH. The NT's expertise covers both somatic medicine and mental health. In LMICs the physical impact of inter alia poverty, abuse, birth complications and sequelae connected to infectious diseases on mental health is substantial. Teaching health personnel about young people's mental health in this context requires competence in both somatic and mental health. The aim of the program has been capacity building in the multidisciplinary team working at Caritas-CCAMH.

Each year, the NT presented summaries from meetings with the Caritas-CCAMH staff at the end of their stay to obtain their verbal evaluation and suggestions for the next year's program. Workshop participants also gave structured evaluations of the workshops. In addition, every year the NT presented a written evaluation to the sponsors of the program (listed under "Funding"). This material provides the basis for the section "The program: Topics, planning and implementations" below.

\section{The program: Planning, topics and implementation}


During the capacity building program, the lessons and workshops were developed in negotiations between the NT and Caritas-CCAMH staff. The topics and schedules were discussed via e-mail beforehand and settled in meetings on the first days of the NT's visit at Caritas-CCAMH. The schedule was regularly changed according to progress of the training program during the two weeks. Gradually the management group at Caritas-CCAMH took more responsibility not only for the practical organization of the workshops, but they have also increasingly contributed during the workshops. The topics proposed were usually based on the evaluation of the previous year's sessions and a desire for further development of specific topics, but also on the actual clinical situation at Caritas-CCAMH, new patient groups and the developmental plans for Caritas-CCAMH. Repetition of material from previous years often preceded implementation of new issues.

The NT has taken part in the clinical work at Caritas-CCAMH and at their satellite clinics in villages and remote sites. As part of the program, the NT followed consultations and discussed specific cases with the staff.

For the topics and teaching approaches in the program, see Table 1. There has been a gradual shift from normal motor, cognitive and emotional development over neurodevelopmental problems to mental health disorders, treatment and interventions. Epilepsy, pharmacological treatment, and mental sequelae of the general risk factors towards health and wellbeing of children in Cambodia were persistent topics, as were understanding and skills in assessments and interventions concerning abuse, neglect, malnutrition, children affected by HIV/AIDS, and cerebral infections (e.g., tuberculosis and malaria). Other topics addressed in the past have been newborn screening and group interventions for anxiety, psychosomatic complaints and interventions for siblings and parents of children with disabilities. 


\begin{tabular}{|c|c|c|}
\hline Year & Topics * & Teaching approach \\
\hline 2005 & Basic understanding & Lessons \\
\hline $2006-$ & $\begin{array}{l}\text { Development (motor, cognitive, emotional)/developmental delay (ID, } \\
\text { autism, specific developmental delays) }\end{array}$ & + \\
\hline 2007 & \multirow{2}{*}{ Assessment (bio-psycho-social approach) } & Case discussions \\
\hline 2008 & & + \\
\hline 2009 & \multirow{3}{*}{$\begin{array}{l}\text { Relevant disorders for CCAMH (PTSD, dissociation, abuse, neglect, } \\
\text { autism, epilepsy, behavior problems, psychosis, anxiety, Tourette } \\
\text { syndrome, medical causes for mental disorders, HIV, cerebral } \\
\text { tuberculosis, and malaria) }\end{array}$} & Role play \\
\hline $2010-$ & & + \\
\hline 2014 & & Demonstration with \\
\hline $2015-$ & + & mother dyads) \\
\hline 2016 & Interventions & + \\
\hline \multirow[t]{17}{*}{2017} & Behavior problems, ADHD & \multirow{3}{*}{$\begin{array}{l}\text { Video and one-way- } \\
\text { window to } \\
\text { demonstrate role } \\
\text { play or real } \\
\text { situations }\end{array}$} \\
\hline & + & \\
\hline & CBT approach (depression, anxiety, PTSD) & \\
\hline & Family counselling & + \\
\hline & + & \multirow{13}{*}{$\begin{array}{l}\text { Guidance on real } \\
\text { consultations via } \\
\text { one-way window or } \\
\text { video }\end{array}$} \\
\hline & Relevant theoretical topics & \\
\hline & Nutrition/malnutrition & \\
\hline & Orphaned vulnerable child & \\
\hline & Resilience & \\
\hline & Psychopharmacology & \\
\hline & + & \\
\hline & Skills & \\
\hline & Newborn observation and screening, education of new mothers & \\
\hline & Relaxation techniques & \\
\hline & $\begin{array}{l}\text { Communication with children (play- and drawing-based } \\
\text { interventions, narratives) }\end{array}$ & \\
\hline & + & \\
\hline & CBT workshop, behavior management, group interventions & \\
\hline
\end{tabular}




\begin{tabular}{|c|c|}
\hline Year $\quad$ Topics * Teaching approach \\
\hline+ \\
Therapeutic alliance
\end{tabular}

The NT created handouts from the theory sections, translated to Khmer. The participants often brought with them the handouts from earlier years to the lessons and used them as basis for building in new knowledge. For the first six to eight years, the education was an opportunity for the entire staff, and the aim was to build on their common knowledge base. Later, the different professional groups also had separate teaching sessions according to their clinical tasks, and personnel from collaborating organizations, such as NGOs, were invited in.

In addition to lectures, the teaching was comprised of case discussions, practical training using role-play, small group discussions, use of one-way mirror observations of live cases, and reviews of videos of clinical consultations and groups. Case presentations were a central element. The second year, members of the staff took over this task and prepared case presentations according to the planned topics. The cases were examined using structured models $(20,21)$ to raise awareness that mental health problems of young people must be assessed from a bio-psycho-social perspective (21). In addition, awareness of individual resilience (23) was repeatedly addressed.

Insert Table 1 here

\section{Reflexivity}

It may be challenging to be part of a competence building program in a multidisciplinary team in an unfamiliar culture and different socio-economic context. To overcome some of these challenges, the NT emphasized collaboration and used relevant cases to illustrate the topics with thorough case discussions and evaluations of both oral and structured feedback from the participants as a base for further progression of the program. These strategies are in accordance with reflective practice education $(24,25)$. Therefore, concepts of reflection-in-action and reflective practice $(25,26)$ have been normative for planning and implementation of the program. Schön (26) claimed that mastering the complex relation between theory and practice is based on the capacity to reflect in action and relates to one's conduct while undertaking the task. This allows both teacher and learner to modify what (s)he is doing while doing it. Mann et al. (25) argued that facilitating reflection, as described above, may assist learners in connecting and integrating new learning into existing knowledge and skills.

\section{Methods}


With reflexivity as a frame of reference for developing the capacity building program, the content and aims of the program changed and developed throughout the 14-year period. Furthermore, the program was not initially planned as a research project. For these reasons, we could not perform a reliable evaluation based on pre-post testing (27). To examine the process, we chose a qualitative research approach with focus-group interviews (28) as the data collecting method to gain insight from the staffs' point of view.

\section{Data collection and participants}

We conducted focus-group interview with 11 Caritas-CCAMH staff members who had taken part in the program for at least two years. The participants worked together on a daily basis and knew each other well. We wanted to recruit all members, but for practical reasons the final sample comprised 11 staff members. The sample comprised three nurses (two women), two psychologists (both women), one special educator (woman), one social worker (woman), one speech therapist (woman), one occupation therapist (man), one art therapist (man), and one program administrator (woman). They had been employed at Caritas-CCAMH for two to 20 years (mean ten years). Caritas-CCAMH have a rather stable personnel group. However, we paid special attention to include two members who had been employed for only two-three years to get their impressions as novices. We distinguish quotes from novice and senior staff in the results section. The interview was audio taped and transcribed verbatim. Two of the authors administered the interview. PP was the moderator and BJ the secretary. The main questions were about the participants' overall impressions of the clinical program, the influences of the program both personally as clinicians and in Caritas-CCAMH, what topics had been valuable, what had not, and their suggestions for further training (see Appendix).

All participants took part in the interview. However, there were differences in their levels of involvement. Most often, they exchanged reflections on the questions raised, but sometimes only gave short answers. This was especially pronounced towards the end of the interview where the issues were their evaluation of the importance of the specific topics during the program and their desires for the future.

\section{Analysis}

The results are based on a thematic analysis (29) of the text from the transcription of the focus-group interview, translated into English. The analysis began by all authors reading the transcripts and exchanging immediate impressions and thoughts. Then, JB and $\mathrm{MH}$ read it thoroughly and identified subordinate interpretations/sub-themes. $\mathrm{MH}$ integrated them into four overarching themes forming the result section of the present article (see Table 2). The concepts of reflection on action and reflective practice (26) were theoretical support (30) during the analysis. During this process we continually went back to the written material from the development of the project to seek validation for our interpretations of the transcripts. 
Table 2

The analytic process from thorough reading of the full text to the identification of sub-themes and the search for overarching themes

\begin{tabular}{|l|l|}
\hline Sub-themes & Overarching themes/results \\
\hline Exchange & Participatory learning \\
Partnership & \\
Continuity & \\
Multidisciplinarity & Integration of theory and practice \\
\hline New knowledge & \\
Integration of theory and practice & \\
Skills as most important & \\
Cases as starting point & \\
The 4-foot model & \\
Cognitive behavioural therapy & \\
Training skills & \\
Lack of follow up & \\
\hline $\begin{array}{l}\text { Learning in situ } \\
\text { Newborn screening }\end{array}$ & Learning in clinical situations \\
Modelling & \\
NT's* friendly attitude & \\
\hline $\begin{array}{l}\text { Building self-confidence by mastering } \\
\text { skills } \\
\text { Relief from unrealistic expectations } \\
\text { Job satisfaction }\end{array}$ & \\
Confidence from clients and partners & \\
\hline $\begin{array}{l}\text { Topics in past and future } \\
\text { Improve English }\end{array}$ & \\
\hline *Norwegian team & \\
\hline
\end{tabular}

\section{Results}

The engagement in the discussions was not so much on specific questions on topics as on how this program had changed them as professionals, their clinical practice and Caritas-CCAMH. Although one of the participants said, "changes are difficult to explain", we obtained rich material and found four 
overarching perspectives during the analysis: participatory learning process, integration of theory and practice with an emphasis on skills, learning in real clinical situations and building self-confidence and job satisfaction.

\section{"All topics were relevant because we chose them"-participatory learning process}

Participants described having partnerships or collaborations with different experts from abroad. The experts provided them with new knowledge that had been adapted to the Cambodian context so as to be useful for the staff. Then, the experts had to learn from the staff at Caritas-CCAMH and a mutual learning process was going on. One senior staff member said:

I think experts from abroad learn from other developing countries like us. And we get new experiences that the experts can use in their countries as well. They adapt them to fit with our country.

Another senior participant added:

They [the NT] shared experiences with us, and we had some points to share with them. For example, we helped with cases and those cases were difficult, so they shared with us how to help.

The participants experienced an exchange of knowledge enhanced over time. They emphasized the importance of the discussions of topics for the program beforehand and during the stay. This was the background for statements that all the topics have been relevant for Caritas-CCAMH; that is, the topics were chosen in collaboration with the NT. As one participant said, "Usually, before taking any topics, they asked us to choose and always asked for ideas from our team."

The Caritas-CCAMH team is multidisciplinary comprised of professionals with various backgrounds concerning knowledge and experiences. The participants stated that essentially the multidisciplinary nature of the NT (i.e., a pediatrician, a child and adolescent psychiatrist and a child psychologist) was an advantage when selecting issues for the teaching blocks to fit the needs of the staff. They reflected that for instance children with autism and intellectual disability may also have emotional problems. However, when the training did not match the everyday work and if there was too much information, it could be difficult for them to follow when they could not apply the issues to their own practice.

The participants described the program as a "meeting between experts". The NT members were experts on different aspects of children's mental health while the staff members were experts on the Cambodian context; children's health risks, the availability of resources, etc. Participants emphasized their active participation in developing the teaching block and the flexibility of the program, both before and during the NT's stay. This required an ability of the NT to modify the teaching process while they were actually doing it, that is, to reflect in action.

\section{"Theory applied with cases and skills is crucial"-integration of theory and practice}


The participants characterized their knowledge about young people's MNDD as superficial and said that their education was not "deep enough" and that they to a small extent, had learned the skills needed to manage children's mental health problems before they started working at CCAMH. They all agreed on the need for new knowledge and that the learning was most effective when the teaching combined theory and practice. To facilitate that, they emphasized the value of applying theory in the analysis of cases from the daily clinic. One senior male participant said:

We brought our own cases for the discussion. We took part in analysing and assessing the case with them to come up with a plan for how to change the child's behaviour.. . Therefore, this is different from class teaching.

A novice added:

Theory combined with practice makes us learn faster. .. And without practice, theory never becomes skill.

Participants summarized that knowing how to analyse a case is the first step to applying a skill, and frequently repeated that learning skills was an important aspect of the teaching. A senior staff member reflected:

So, they told that "if we have knowledge, we need skills." For example, if children threw things, how should we handle this? If we did not have skills, we did not know how to help children. Therefore, we have to have skills to succeed in our work. Some people are good at talking, but not doing. To help children, you should have knowledge and skills.

However, skills can be difficult to learn within the frame of the one/two-week's courses the NT provided and the participants asked the team to stay longer. To some extent, this could be compensated with repetition over years. Participants recalled, as an example, a workshop on cognitive behaviour therapy (CBT). After three days, the session had to start over from the beginning; the concepts were unfamiliar and the skills were complex. The training in the CBT approach was repeated in later workshops and different situations. For some of the participants, that meant they had got a basic understanding and said it had been useful for them to apply this thinking in their daily practice.

An example of the interactive learning with repetition is a senior female therapist rendering from a workshop on management of children's behaviour problems:

The teacher made a table and asked us to fill [it] in. .. and then she showed us the proper places. We noted that we put things in the wrong places. Then we knew the right places after the mistake. Later we practiced with clients. At first things did not go smoothly. But after practicing again and again, we felt confident in helping clients and asking questions.

To be able to practice the new skills in clinical work, participants said the training was necessary. Some participants mentioned that some staff lacked commitment and they went on as usual, for example, by 
continuing their routine without changing to a broader bio-psycho-social-inspired assessment. Participants reflected that maybe a structure for following up the new knowledge was missing.

Participants gave examples of how useful cases from their daily clinic were for them to connect the new knowledge to their everyday clinical work. The learning process shifted between theory and practice with frequent repetitions in the actual session, but also the topics and skills could be an issue in later sessions. They expressed high appreciation for the opportunities for feedback and reflections both on the content and the process.

\section{"It opened my eyes widely"-learning in real clinical situations}

Many said they had vivid remembrances of clinical demonstrations, for instance, the pediatrician training them in newborn baby screening. They described how the pediatrician screened newborns in hospital, and then supervised staff at health centres. This awareness in observation was transferred to other situations, for instance, to observe children at all ages when they come to consultations-to assess their appearance, hygiene, drooling, nutritional status, etc. They also mentioned that from the abovementioned demonstrations they learned to pay attention to the parents as well. A senior nurse said:

I learned how to communicate with mothers, for example, when we did newborn screening at health centres; we always asked the mothers "how are you?" Before, I was not aware of this.. . This is what I learned: when the young patients come, do not forget to talk with the parents.

Some elaborated further on this and recalled from other sessions that the therapist has to reach a consensus with the parents on the nature of the problem, how to understand it and what to do about it. They remembered the repetition of the concept of "therapeutic alliance." After observing the NT's consultations and having had their supervision on real consultations on video or through the one-way mirror, they said they felt more comfortable starting a consultation. One senior male nurse said, "They have offered us skills on how to sit with clients, how to listen to clients and how to ask [questions]. Those are skills that we do in practice with clients, not [just] theory."

Participants explained that they had learned these skills, to a large extent, unconsciously, regardless of their professional background, just by being present. The NT's attitude facilitated their learning; as one novice staff member said, "I want to say about communication... for example, she listened to us, asked us questions."

The NT team was characterized as polite and friendly, almost like friends. Some added that maybe because of this closeness, the NT too often said "yes." Sometimes the staff actually needed frank feedback, even if it was negative, to learn. A staff member been at CCAMH for six years said "They do not need to please us".

They remembered this learning in clinical situations as pegs for memory, as one said: "I still remember this as if it was the last lesson." However, most of the cases for discussion were prepared from the files, 
and demonstrations were done through role-play. Many stated that they missed learning in real situations.

Regardless of background knowledge and profession, all the participants mentioned observing the NT in consultations and clinical procedures or having gotten supervision in clinical situations. They evaluated this learning highly and talked about transferring knowledge and skills from one situation to another. This modeling and acquiring of tacit knowledge seemed to have been facilitated by what was experienced as the NTs friendly attitude.

\section{"The changes are not only for clients, but ourselves as well"-self-confidence and job satisfaction}

This capacity building program, in their perception, changed their thinking, feelings and behaviour. Concerning thinking, they mentioned empathy for the client and knowing how to analyse them. Concerning feelings, they said they had gained confidence in and enjoyment of their work. As a senior nurse said:

Like others have said, we get knowledge without [conscious] awareness, for example, skills in communication. We have improved a lot now. We have confidence in working with clients. If we had not, we would feel unease, cold hands, cold feet and sweating.

Concerning behaviour, they gained the skills to do their work. Acquiring skills and self-confidence were closely related. They said that when they had skills and knew what to do, they felt self-confident, which made the work more effective. However, there would be cases that were out of their reach and could not be alleviated. One senior therapist recalled once she had presented a case that never improved, she felt bad as a therapist:

She said there must be one or some who are not [getting] better, despite [our] efforts. Therefore, there is no need to feel bad [about this case].. . So after I met her, I felt relieved.. . I never blame myself anymore.

Circumstances outside the therapy room that the therapist could not influence, might have had a negative impact. For that participant, acknowledgement of her helplessness in these situations changed her attitude when seeing clients.

The challenges for professionals in the field of children's MHDD problems in LMICs are tremendous, and the staff said that they could sometimes feel "anxious, sweating and fearful." Mastering clinical skills and acknowledging the limits of their mandate supported the participants' self-confidence. The learning strategy inspired by reflective practice seems to have assisted the participants in integrating the affective aspects of the therapist role.

\section{Discussion}

The current analysis of a Cambodian-Norwegian continuing professional development (CPD) program showed that the knowledge and skills exchange held in the framework of dialogic partnership, particularly 
over significant period of time, contributes to learning across cultures. The results have several implications for how a cross-cultural CPD program can be enhanced. For example, some participants mentioned that they would have preferred that the NT came more frequently and for longer stays. This indicated that the current two-week framework is perceived as suboptimal concerning learning therapeutic methods and interventions targeting specific mental health diagnostics. The time span each year may be too short despite the repetition over years. Continuous development of mental health service tasks may, in addition, require another kind of continuity and intensity than our project can offer.

However, despite these practical limitations, it is important to consider the opportunities the current framework provides according to the participants. Over the years, the topics of teaching intentionally moved from normal development towards developmental delay and bio-psycho-social problems. This knowledge base, combined with clinical cases and the teachers' demonstrations and active participation in the daily clinical work, provided a platform for the staff to adapt basic relational attitudes, build selfconfidence and enhance job-satisfaction. Kokota et al. (13) recently examined a two-day training program on mental health topics for primary health professions in Malawi. They found that scores in knowledge and confidence in identifying mental disorders were significantly higher immediately after the training and six months thereafter. The participants' attitude towards mental illness and mentally ill was not changed when scored by instruments that measure benevolence, authoritarianism and primary health ideology. Possibly, the strength of our program is its long duration and stability that seems necessary to build competence in therapeutic skills like empathy and therapeutic alliances.

The concepts of reflection in action and reflective practice $(25,26)$ guided the development of the program and provided a conceptual background for the analyses. We found that these concepts were helpful in promoting the changes the participants describe "in thoughts, feelings and behaviour" and "in ourselves and in Caritas-CCAMH." Participants provided examples of collaborative planning, frequent feedback and repetition upon the participants request, all requiring that the teachers have the ability to modify the teaching process while performing it. They highly evaluated the facilitation of reflection both on the content and the process in the integration of theory and practice. The extensive use of actual cases from the clinic and the NT's participation in the clinic and demonstration of clinical procedures seemed to have promoted this. Naidu and Kumagai (31) have commented on exporting the concept of reflective practice for a global medical education audience. They claim that globalization of medical education demands critical reflection on the reflection itself. They urge educators to "aspire to turn exportation of educational theory into a truly bidirectional, collaborative exchange in which culturally conscious views of reflective practice contribute to humanistic, equitable patient care." In the actual project, we have put emphasis on collaborative learning, and the participants used the word "partnership." It is probably impossible to eliminate the cultural "white spots" or taken-for-given perspectives in Western clinicians' performances (32), but we would argue that we have paid critical attention towards our practice. We have learned that reflective practice combined with critical reflection on practice have secured the relevance of the project, as is supported by the present evaluation from the staff. Our conclusions are in accordance with the recommendations for "Value-driven Training Innovation" in global mental health from the Society for the Study of Psychiatry and Culture (33). 
The participants overall gave a positive description of the NT, describing them "almost like friends". Some participant, however, expressed the view they missed frank feedback, even if it was negative, to learn better. Maybe this tells about a cultural difference in communication between Scandinavia and SouthEast Asia. The NT team's reflective stance by listening, exploring and discussing a topic, was sometimes interpreted as friendly and pleasing in a cultural context where the communication could be direct and unilateral.

Caritas-CCAMH is a clinic for child mental health care with a multidisciplinary team of doctors, psychologists, nurses, special pedagogue, social worker, occupational therapist and art therapist. The staff appreciated the program because it rendered them "new knowledge". Caritas-CCAMH needed staff with a basic common knowledge in MNDD in young people, and the different professions needed knowledge adapted to their specific tasks. There is a balance to find when the teaching focuses on the whole group of staff or is given to selected groups. In collaboration with the staff in planning and implementation, it seems we have reached this balance reasonably well, but some of the participants said that the lessons were hard to follow when the topics did not match their daily work.

\section{Strengths and Limitations}

To our knowledge, few studies have brought forward the staff's experiences from CPD projects mediated by Western experts to a team in child and adolescent mental health in LMIC. Our participants emphasized the importance of learning by participation, integration of theory and practice and modeling, which have got little attention in the literature regarding capacity building in a global context.

The empirical data to this project is from one focus group only. We wanted to include as many as possible of the staff, and 11 of the staff were available in addition to those two who administered the interview. We might have divided this group into two, and possibly got some more aspects and deeper understanding (28). However, CCAMH is a busy clinic, and it turned out to be difficult to organize two groups. Despite this limitation, we got rich, varied and valid descriptions, and we are aware that there may be more aspects that our project did not catch.

The current analysis has several possible biases. The first is that the documents following the development of the project were recorded by the NT from their perspective except for the participants' structured evaluation after each session. The second is that the leader of the psychology team at Caritas$\mathrm{CCAMH}(\mathrm{PP})$ headed the focus-group discussion and the manager (BJ) was present, but did not take part in the discussion. The participants may have been reluctant to bring negative experiences to the attention of the leaders and their colleagues (34), and the overall positive accounts from the program may be a result of this. In this context, we could only, to a small extent, expect to get negative comments about the program, although the participants also reported some challenges and sort-comings. We could not get the complete picture, but we evaluated what the staff said and analysed it with this bias in mind. We therefor determine the results to be new and valid, although not complete. 
The program started 14 years ago. Some of the participants had not followed the project from the beginning, and in the interview, they mainly referred to topics from recent years regarding learning skills, interventions and therapeutic alliance. As one participant said, "Change is difficult to explain". The background material reveals a gradual development of the program as a result of the feedback process together with the staff (see Table 1). There has been a process from more general topics relevant for all staff to more specialized topics and practices, and a gradual development to more involvement of the staff concerning organization and participation in the lessons and practice. The participants to a small extent refer to this process; however, we think this is a basis for their present evaluation.

\section{Conclusions}

Our results bring forward attitudes and perspectives developed over the years. We believe this can be a valuable contribution to the different interventions developed, performed and evaluated to enhance the mental health of children and adolescents in $\operatorname{LMICs}(12,13,14,17)$. We give a case that illustrates the main opportunities of a CPD characterized by collaboration, short intervals of training, long duration and a stable team of experts from abroad. The most salient points are:

- Foreign experts' reflexive attitude of collaboration in planning and implementation and continuous changing of the program according to feedback from the staff is crucial.

- Teaching should represent an integration of theoretical presentations and practical training from a bio-psycho-social perspective.

- Presentations and analyses of cases from the clinic are a useful way to secure relevance and explore cultural differences between the contexts of staff and teachers.

- Live observations and/or videos enhance learning of clinical skills and attitudes, modeling, team discussions and reflections.

- It could be valuable, when it is possible, to plan measures to facilitate the practice of the new knowledge once the experts have left.

- The two-week framework is suboptimal for learning therapeutic methods and interventions targeting specific mental health diagnosis.

To conclude, the model described herein of low investment and low intensity may be feasible for Western professionals with the ambition to support institutions for child and adolescent mental health in LMICs over years.

This article is not published nor under publication elsewhere.

\section{Abbreviations}

Caritas-CCAMH Caritas Center for Child and Adolescent Mental Health

CBT Cognitive behaviour therapy

Page $16 / 21$ 
CPD Continuing professional development

LMIC Low- and middle-income country

MNDD Mental health and neurodevelopmental disorders

NT Norwegian team

WHO-AIMS Assessment Instrument for Mental Health Systems

WHO mhGAP World Health Organization Mental Health Gap Action Program

\section{Declarations}

\section{Ethical approval and consent to participate:}

According to the Regional Committee for Medical and Health Research Ethics, Western Norway, the Act does not apply to this project (Ref.no.193125).

Participants were provided with information on the study. Written informed consent to participation was obtained from participants. They were free to withdraw from the study any time without any consequences for their work situation. All data are anonymized and stored securely.

\section{Consent for Publication}

The participants have signed a consent for publication of the results in an international scientific journal.

\section{Availability of data and material}

The datasets used and analysed during the current study are available from the corresponding author on reasonable request.

\section{Competing interest}

The authors declare that they have no competing interests.

\section{Funding}

- The Norwegian Council for Mental Health, Oslo, Norway, funding by travel grants to MH and GAA 2005-2008

- Regional Centre for Child and Youth Mental Health and Child Welfare, Norwegian Research Centre AS NORCE, Bergen, Norway, funding by travel grants to MH and GAA 2009-2016

- The Global Mental Health Research Group, Centre for International Health, University of Bergen, Norway, funding by travel grants to MH and GAA 2017-2018

- Department of Psychology, University of Oslo, Norway, funding by travel grant to KF 
- Frambu Resource Centre for Rare Disorders, Siggerud, Norway, funding by travel grant to KF

\section{Authors' contributions}

PP and BJ performed the interview. All authors read the transcripts and had a preliminary exchange of reflections. JB and $\mathrm{MH}$ read the transcripts thoroughly. $\mathrm{MH}$ did the analysis and did the write-up. All authors commented on drafts and approved the final version.

\section{Author's information}

Marit Hafting: MD, PhD, Child and adolescent psychiatrist. Retiree. Till February 2020 Senior Consultant Haukeland University Hospital, Bergen, Norway. Till 2018 part time Researcher Regional Centre for Child and Youth Mental Health and Child Welfare, NORCE AS, Bergen, Norway

Pat Puthy: Psychologist, PhD student. Team leader Caritas-CCAMH, Cambodia,

Gunn Aadland: MD, Pediatrician. Senior consultant Pediatric department University Hospital of Stavanger, Norway

Krister Fjermestad: Child Psychologist, PhD. Professor Department of Psychology, University of Oslo, Norway

Bhoomikumar Jegannathan, MD, PhD, Child and Adolescent Psychiatrist, Director and Consultant CaritasCCAMH, Cambodia

\section{Acknowledgements:}

We thank:

- The staff of Caritas-CCAMH for their participation,

- Ms Nget Theary for transcribing the interview and translating from Khmer to English,

- Jone Schanche Olsen for having been to great support by reading and commenting on drafts and versions of this manuscript.

\section{References}

1. World Health Organization. Mental health action plan 2013-2020. Geneva: World Health Organization; 2013.

2. Erskine HE, Moffitt TE, Copeland WE, et al. A heavy burden on young minds: the global burden of mental and substance use disorders in children and youth. Psychol Med. 2015; 45: 1551-63. Available from: doi: 10.1017/S0033291714002888.

3. Lu C, Li Z, Patel V. Global child and adolescent mental health: the orphan of developmental assistance for health. PLoS Med. 2018. doi.org/10.1371/journal.pmed.1002524. [Internet]. 
4. The Lancet Commission on global mental health and sustainable development. The Lancet Commissions. 2018;392(3):1553-98. doi.org/10.1016/S0141-6736(18)31612-X. October 27.

5. Klasen $\mathrm{H}$, Cromberg A-C. What works where? A systematic review of child and adolescent mental health interventions for low and middle income countries. Soc Psychiatry Psychiatr Epidemiol. 2013;48:595-61. doi.org/10.1007/S00127-012-0566-X.

6. Kieling C, Baker-Henningham $\mathrm{H}$, Belfer $\mathrm{M}$, et al. Child and adolescent mental health worldwide: evidence for action. Lancet. 2011;378:1515-25.

7. Rocha TB, Graeff-Martins AS, Kieling C, Rohde LA. Provision of mental healthcare for children and adolescents: a worldwide view. Curr Opin Psychiatry. 2015;28(4):330-5. doi:10.1097/YCO.0000000000000169.

8. Juengsiragulwit D. Opportunities and obstacles in child and adolescent mental health service in lowand middle- income countries: a review of the literature. WHO South-East Asia J Public Health. 2015;4(2):110-22.

9. World Health Organization Assessment Instrument for Mental Health Systems. WHO-AIMS. Version 2.2. Geneva: World Health Organization; 2005.

10. mhGAP: Mental Health GAP Action Programme, scaling up care for mental, neurological and substance use disorders. World Health Organization; 2008.

11. Kohrt BA, Jordans MJD, Rai S, Shrestha P, Luitel NP, Ramalya MK, Singla DR, Patel V. Therapist competence in global mental health: development of the Enhancing Assessment of Common Therapeutic factors (ENACT) rating scale. Beh Res Ther. 2015;69:11-21. doi.org/10.1016/j.brat.2015.03.009.

12. Akol A, Nalugya J, Nshermereirwe S, Babirye JN, Engebretsen IMS. Does child and adolescent mental health in service training result in equivalent knowledge gain among cadres of non-specialist health workers in Uganda? A pre-test post-test study. Int J Ment Health Syst. 2017;11:50. doi:10.1186/s13033-017-0158-y.

13. Kokota D, Lund C, Ahrens J, Breuer E, Gilfillan S. Evaluation of mhGAP training for primary healthcare workers in Mulanje, Malawi: a quasi-experimental and time series study. Int J Ment Health Syst. 2020;14:3. doi.org/10.1186/s13033-020-2337-0.

14. Murray LK, Dorsey S, Bolton P, Jordans MJD, Rahman A, Bass J, Verdeli H. Building capacity in mental health interventions in low resource countries: an apprenticeship model for training local providers. Int J Ment Health Syst. 2011; 5:30. Available from: http://www.ijmhs.com/content/5/1/30.

15. Fung DS, Lim-Ashworth NS. Child psychiatry without psychiatrists: a new model for old problems. Ann Acad Med Singapore. 2017;46:42.

16. Fricchione G, Borba CP, Alem A. Capacity building in global mental health: professional training. Harv Rev Psychiatry. 2012;20:47-57.

17. Tareen A, Mirza I, Minhas A, Minhas F, Rahman A. Developing a child and adolescent mental health service in a low-income country: a global partnership model. Psychiatric Bul. 2009;33:181-3. doi:10.1192/pb.bp.108.020487. 
18. Jegannathan B, Kullgren G, Deva P. Mental health service in Cambodia, challenges and opportunities in a post-conflict setting. Asian J Psychiat. 2015;13:75-80. doi.org/10.1016/ajp.2014.12.006.

19. Caritas -CCAMH. 2020. Available from: http://www.caritascambodia.org/ccamh/.

20. Garlov I. Kartleggingsverktøy til hjelp i daglig arbeid og samarbeid når vi er bekymret. (Assesment tool for assessment and multidisciplinary cooperation). Stavanger: Stiftelsen Psykiatrisk Opplysning; 2006.

21. Winters NC, Hanson G, Stoyanova V. The case formulation in child and adolescent psychiatry. Child Adolesc Psychiatr Clin N Am. 2007;16:111-32. doi.org/10.1016/j.chc.2006.97.010.

22. Engel GL. The need for a new medical model: a challenge for biomedicine. Science. 1977;196:12936. doi:10.1126/science847460.

23. Masten AS. Resilience in developing systems: progress and promise as the fourth wave rises. Dev Psychopathol. 2007;19:912-30. doi:10.1017/S0954579407000442.

24. Clara M. What is reflection? Looking for clarity in an ambiguous notion. J Teac Educ, May 2015 (first published Oct 2, 2014). doi: 10.117710022487114552028.

25. Mann K, Gordon J, MacLeod A. Reflection and reflective practice in health professions education: a systematic review. Adv Health Sci Educ Theory Pract. 2009;14:595-621. doi:10.1007/s10459-0079090-2.

26. Schön D. The reflective practitioner. London: Arena, Ashgate Publishing; 1991.

27. Patton MQ. A utilization-focused approach to contribution analysis. Evaluation. 2012;18:364-77. doi.org/10.1177/1356389012449523.

28. Kitzinger J. Qualitative research: introducing focus groups. BMJ. 1995;311:299. doi.org/10.1136/bmj.311.7000.299.

29. Braun V, Clarke V. Using thematic analysis in psychology. Qual Res Psychol. 2006;3:77-101. doi:10.1191/147808887066pq063oa.

30. Malterud K. Theory and interpretation in qualitative studies from general practice: why and how? Scand J Pub Health. 2016;44:120-9. doi:10.1177/1403494815621181.

31. Naidu T, Kumagai A. Troubling muddy waters. Problematizing reflective practice in global medical education. Acad Med. 2016;91:317-32. doi:10.1097/ACM.0000000000001019.

32. Summerfield D. How scientifically valid is the knowledge base of global mental health? BMJ. 2008;336:992-4. doi:10.1136/bmj39513441030AD.

33. Kohrt BA, Marienfeld CB, Panter-Brick C, et al. Global Mental Health: Five Areas for Value-Driven Training Innovation. Acad Psychiatry. 2016;40:650-8. doi:10.1007/s40596-016-0504-4.

34. Coar L, Sim J. Interviewing one's peers: methodological issues in a study of health professionals. Scand J Prim Health Care. 2006;24:251-6. doi:10.1080/02813430601008479.

\section{Supplementary Files}


This is a list of supplementary files associated with this preprint. Click to download.

- supplement7.docx 